\title{
PERANCANGAN SISTEM INFORMASI PENYEWAAN BUS PARIWISATA DI RIZKY JAYA TRANSPORT BERBASIS JAVA
}

\author{
Aris Kurniawan', Laksana Priyo Abadi², Agus Wilson ${ }^{3}$ \\ Program Studi Informatika, Fakultas Teknik dan Ilmu Komputer, Universitas Indraprsata PGRI \\ J1. Raya Tengah No. 80, Kel. Gedong, Kec. Pasar Rebo, Jakarta Timur 13760 \\ ghechool.28@gmail.com¹, laksanarioabadi@gmail.com², wilsonaw2580@gmail.com³
}

\begin{abstract}
Abstrak
Permasalahan dari sistem pendataan penyewaan bus pariwisata di Rizky Jaya Transport yaitu lambatnya pencarian pendataan pelanggan dalam proses penyewaan. Karena sistem yang diterapkan masih bersifat manual dan belum terkomputerisasi, sehingga peneliti tertarik untuk mengembangkan sistem informasi penyewaan bus pariwisata di Rizky Jaya Transport yang ada saat ini untuk mengatasi kekurangan yang ada. Seiring dengan zaman teknologi yang berkembang, komputer telah mendorong terjadinya perubahan ilmu baik dalam kajian ataupun implementasi dilapangan. Peran teknologi komputer sangat diperlukan oleh berbagai perusahaan. Mengingat kebutuhan akan peningkatan efisiensi dan efektifitas dari setiap kegiatan dalam instansi dilakukan secara cepat dan akurat tanpa adanya dukungan teknologi tersebut. Akurasi data, kecepatan waktu dan relevansi menjadi penentu kualitas informasi yang dihasilkan. Menggunakan metode pengembangan sistem Waterfall pada penelitian ini dengan tahapan seperti rekayasa sistem, analisis, desain, coding, testing, dan maintenance. Hasil dari penelitian ini adalah menciptakan aplikasi untuk penyewaan bus pariwisata yang efektif dan efisien.
\end{abstract}

Kata Kunci : Sistem, Penyewaan, Bus Pariwisata

\begin{abstract}
The problem of the tourism bus rental system in Rizky Jaya Transport is the slow search for customer logging in the leasing process. Because the system applied is still manual and not computerized, so researchers are interested to develop a tourism bus rental information system in the existing Rizky Jaya Transport to overcome existing deficiencies. Along with the era of emerging technology, the computer has encouraged the change of science in both the study and the implementation of field. The role of computer technology is indispensable by various companies. Given the need for increased efficiency and effectiveness of every activity in the institution is done quickly and accurately without the support of such technology. Data accuracy, time speed and relevance become the quality determinant of the resulting information. Using Waterfall system development method in this research with stages such as system engineering, analysis, design, coding, testing, and maintenance. The result of this research is creating an application for the rental of effective and efficient tourism bus.
\end{abstract}

Keywords : System, Lease, Tourism Bus

\section{PENDAHULUAN}

Transportasi sangat memegang peranan penting dalam pembangunan dan pengembangan infrastruktur transportasi. Suatu interaksi yang baik dan ideal antara komponen-komponen transportasi (penumpang, barang, sarana dan prasarana) membentuk suatu sistem transportasi yang komprehensif, efisien dan efektif sehingga diharapkan mampu mengoptimalkan fungsi transportasi dalam suatu kawasan perkotaan.

Tata Sutabri (2012) menjelaskan bahwa sistem merupakan suatu bentuk integrasi antara satu komponen dengan komponen lain karena sistem memiliki sasaran yang berbeda untuk setiap kasus yang terjadi dalam sistem tersebut. Penyewaan adalah suatu perjanjian dengan mana pihak yang satu mengikatkan dirinya untuk memberikan kepada pihak yang lainnya kenikmatan dari suatu barang, selama suatu waktu tertentu dan dengan pembayaran suatu harga yang oleh pihak yang tersebut terakhir itu disanggupi pembayarannya (Subekti, 2014). Sejalan dengan teknologi komputer hampir 
setiap sektor, instansi, atau perusahaan banyak menggunakan dalam kegiatannya. Demikian juga dengan proses penyewaan kendaraan khususnya bus, dimana perangkat komputer sangat dibutuhkan guna memudahkan membuat laporan dokumen setiap arsip dan data operasional lainnya yang sangat berguna untuk membantu kerja karyawan setiap harinya.

Maka adanya pemakaian Sistem Penyewaan Bus yang telah terkomputerisasi banyak sekali keuntungan yang diperoleh seperti informasi data bus ataupun data penyewaan yang tersedia dapat diketahui dengan cepat. Perolehan informasi juga akan lebih efisien di bandingkan dengan cara manual menggunakan buku, mudah-mudahan rancangan aplikasi penyewaan bus ini dapat terus dikembangkan dan bisa digunakan untuk tempat-tempat penyewaan bus ataupun penyewaan transportasi lainnya. Seiring dengan semakin canggihnya teknologi yang berkembang, komputer telah mendorong terjadinya perubahan ilmu, baik dalam kajian ataupun implementasi dilapangan. Peran teknologi komputer sangat diperlukan oleh berbagai perusahaan. Mengingat kebutuhan akan peningkatan efisiensi dan efektifitas dari setiap kegiatan dalam instansi tidak dapat diukur dan dilakukan secara cepat dan akurat tanpa adanya dukungan teknologi tersebut. Akurasi data, kecepatan waktu dan relevansi menjadi penentu kualitas informasi yang dihasilkan.

\section{PENELITIAN YANG RELEVAN}

Zainal Arifin pada penelitiannyan yang berjudul Pembuatan Perangkat Lunak Aplikasi Pemesanan dan Penjualan Sepeda Motor (Studi Kasus: CV. Kharisma Motor) merupakan penelitian yang bertujuan agar sistem pada CV. Kharisma Motor dapat berjalan dengan efektif dan efisien, serta memaksimalkan proses pemesanan dan penjualan motor.

Sedangkan Saeful Falah melakukan penelitian tentang Sistem Informasi Penyewaan Bus PO. Metropolitan. Hasil data yang dikumpulkan di PO. Metropolitan ini masih mengalami beberapa kendala seperti proses pengolahan data penyewaan bus pariwisata, dengan kata lain masih ada proses kegiatan yang dilakukan belum menggunakan sistem terkomputerisasi, sehingga banyak hambatan saat melakukan proses pengolahan data. Maka dari ini peneliti bertujuan ingin membuat suatu sistem yang baru agar pengolahannya menjadi baik dan mempermudah dalam proses transaksi penyewaan bus pariwisata sehingga peneliti dapat mengembangkan suatu sistem yang sedang berjalan dengan membangun perangkat lunak di PO. Metropolitan.

\section{METODE PENELITIAN}

Metodologi pengembangan sistem yang digunakan Waterfall (Jogiyanto, 2010), dengan tahapan seperti gambar sebagai berikut: 


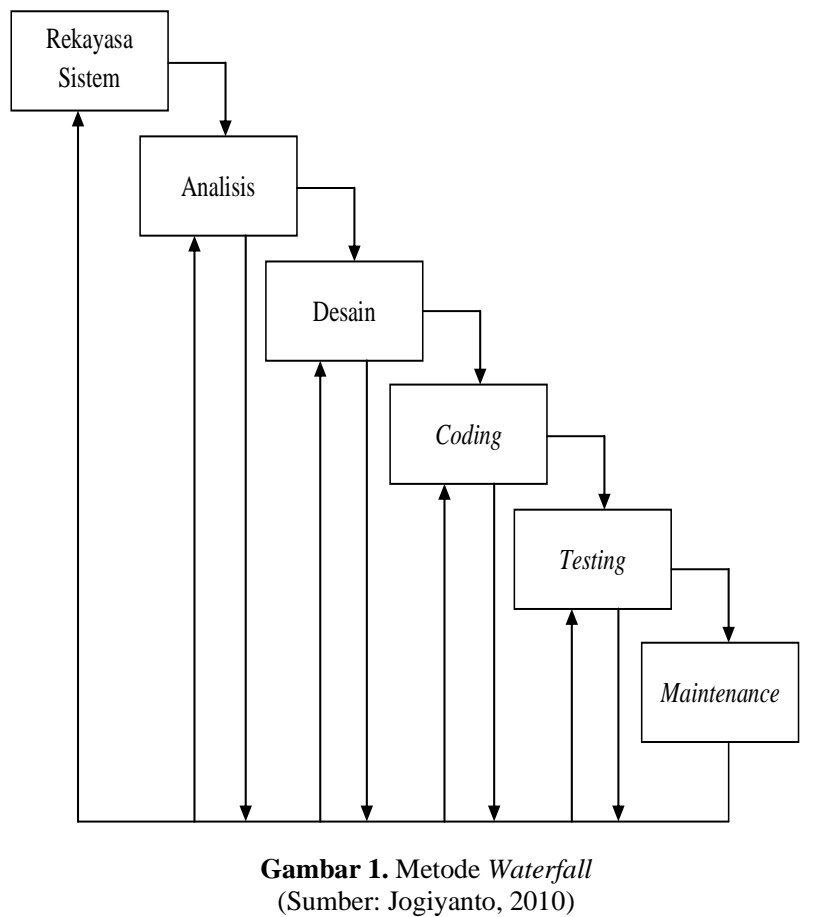

Adapun langkah-langkah dalam metode waterfall dalam penelitian ini adalah sebagai berikut:

1. Sistem Enginering (Pengumpulan Data).

Dalam tahap ini peneliti melalukan pengumpulan kebutuhan seluruh elemen sistem seperti data-data yang digunakan. Dimana elemen-elemen itu dapat menunjang dalam sistem aplikasi penyewaan bus pariwisata di Rizky Jaya Transport.

2. Analysis (Analisis Data \& Proses)

Kemudian pada menganalisa kebutuhan sistem dilakukan pengumpulan dengan berfokus pada perangkat lunak, meliputi Informasi, fungsi masing-masing pada bagian sistem, kerja/cara kerja, antar muka. Lalu menyediakan perangkat dan teknik yang dapat membantu peneliti untuk menentukan kebutuhan melalui sistem informasi penyewaan bus pariwisata dalam melakukan pengolahan data-datanya. Perangkat yang dimaksud adalah penggunaan Diagram Alir Data (DAD) untuk menyusun daftar input, proses dan output fungsi bisnis.

3. Design (Perancangan)

Pada tahap ini dilaksanaan perancangan struktur data, arsitektur perangkat lunak, rincian procedural, karakteristik antar muka dilaksanakan pada tahap ini dan dirancang pada tampilan layar seperti form masukan dan form keluaran dari sistem yang akan dirancang.

4. Coding (Pengkodean)

Pada tahap ini dibuat coding sistem informasi penyewaan bus pariwisata yang merupakan tahap untuk membuat suatu kode tentang aplikasi yang aka dibuat agar dibuat agar dapat dibaca dan diterjemahkan oleh komputer.

5. Testing (Pengujian)

Sebelum sistem informasi penyewaan bus pariwisata digunakan dengan baik, harus dilakukan pengujian terlebih dahulu. Rangkaian pengujian ini dijalankan bersama-sama dengan data aktual dari proses yang sudah ada atau sistem yang sedang berjalan.

6. Maintenance (Implementasi)

Bagian ini merupakan bagian terujung dari siklus perancangan sistem informasi penyewaan bus di Rizky Jaya Transport. Pada tahapan ini dilakukan kegiatan corrective maintenance, yaitu mengkoreksi kesalahan pada perangkat lunak yang baru diketahui pada saat perangkat lunak dipergunakan. Dengan adanya corrective maintenance terhadap sistem penyewaan bus pariwisata. 


\section{HASIL DAN PEMBAHASAN}

\section{Analisa Permasalahan}

Pada sistem informasi penyewaan bus pariwisata di Rizky Jaya Transport ini ternyata mempunyai beberapa kelemahan karena sistem yang digunakan belum sepenuhnya terkomputerisasi. Proses penyewaan bus masih dilakukan secara manual sehingga mengalami hambatan ketika dilakukan pengecekan terhadap data penyewaan yang masuk. Bagian administrasi tidak melakukan pelaporan secara rutin mengingat masalah-masalah yang muncul saat rekapitulasi jumlah penyewaan. Dan proses transaksi pembayaran penyewaan bus dilakukan pada satu bagian sehingga akan menyebabkan duplikasi data bahkan data yang hilang karena proses dilakukan pada satu bagian yang sama. Sehingga pelayanan terhadap pelanggan menjadi tidak efisien dan mungkin akan terjadi kesalahan akibat waktu yang lama dalam pencarian data. Dalam proses pembuatan laporan yang dilakukan secara manual memungkinkan terjadinya kesalahan yang memerlukan waktu yang lama dalam mengubahnya.

\section{Alternatif Penyelesaian Masalah}

Untuk mencari solusi dalam permasalahan yang ada maka peneliti membuat suatu sitem yang akan membantu dalam menyelesaikan masalah tersebut. Dengan pengolahan data yang berhubungan dengan data penyewa ada pada bagian administrasi. Pengolahan data ini akan membuat data tertata rapi sehingga mempermudah dalam pencarian data dan penyerahan laporan kepada pimpinan.

Proses pembayaran penyewaan bus harus dilakukan oleh bagian yang berbeda sehingga masing-masing dapat memberi laporan yang detail tentang penyewaannya. Dan sistem aplikasi administrasi penyewaan bus membantu dalam menyelesaikan pengolahan data penyewa, mengamankan data, dan membuat laporan untuk pimpinan.

\section{Diagram Konteks}

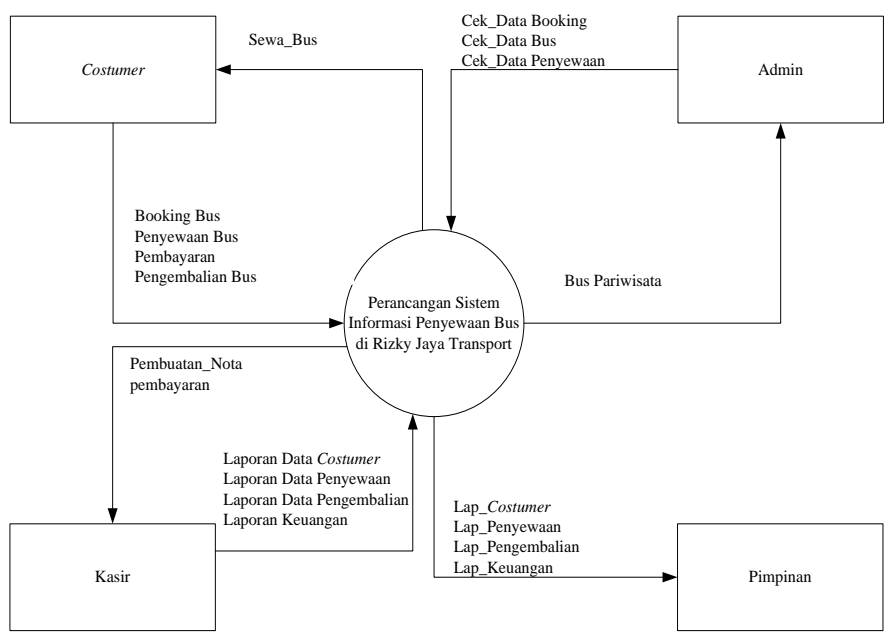

Gambar 2. Diagram Konteks

\section{Normalisasi}

Normalisasi adalah teknik untuk merancang tabel basis data relasional guna meminimalisir duplikasi data sehingga dapat menjaga basis data dari permasalahan unomaly update (Pahlevi, 2013).

Berikut bentuk normalisasi dari sistem informasi penyewaan bus pariwisata di Rizky Jaya Transport: 


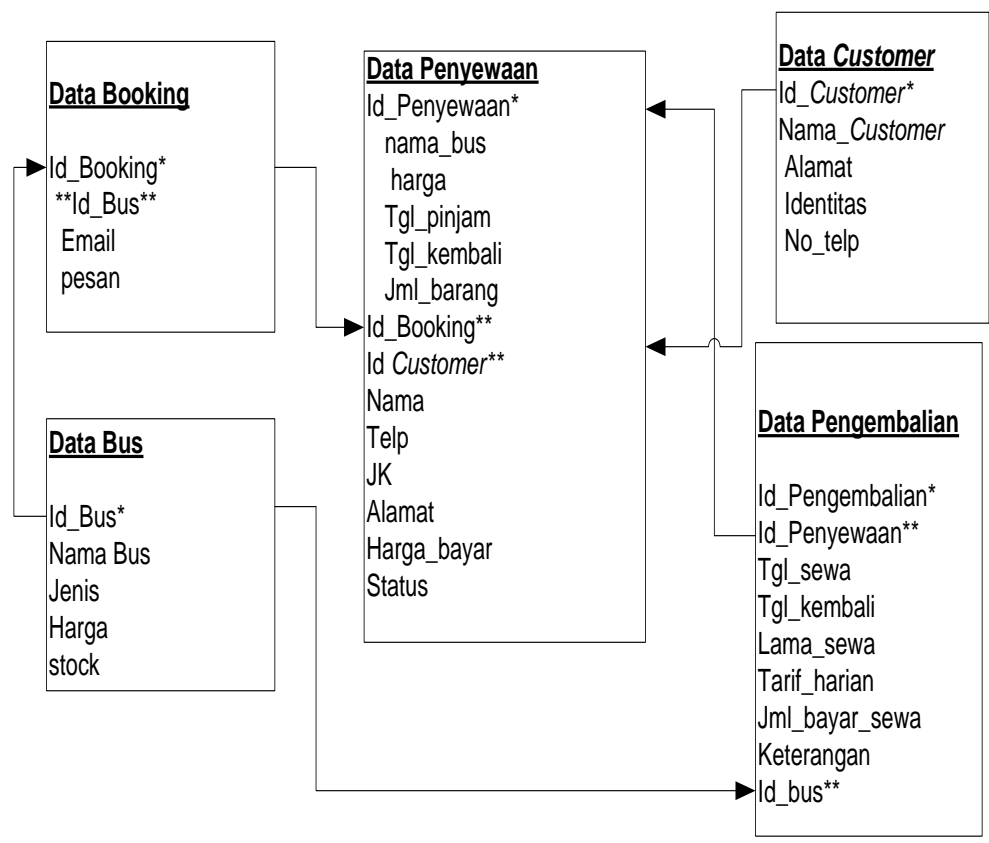

Gambar 3. Normalisasi

\section{Entity Relationship Diagram (ERD)}

Entity Relationship Diagram (ERD) adalah Entity Relationship Diagram (ERD) dikembangkan berdasarkan teori himpunan dalam bidang matematika. ERD digunakan untuk pemodelan basis data relasional (Shalahudin, 2015).

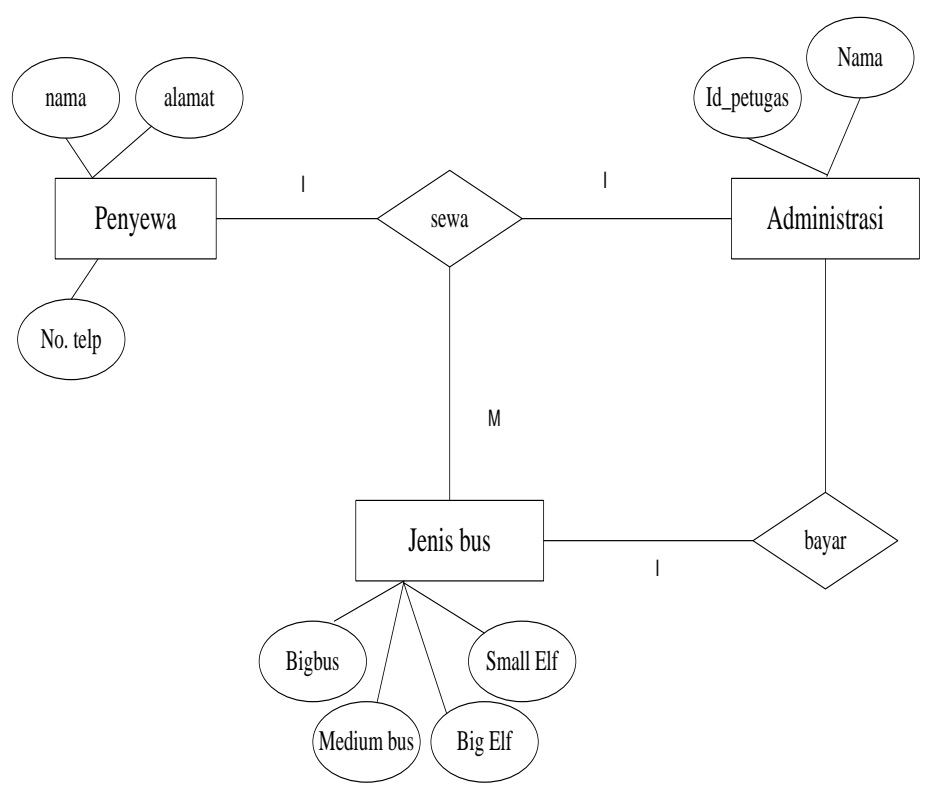

Gambar 4. Entity Relationship Diagram 
Tampilan Layar Sistem

Tampilan Layar Login

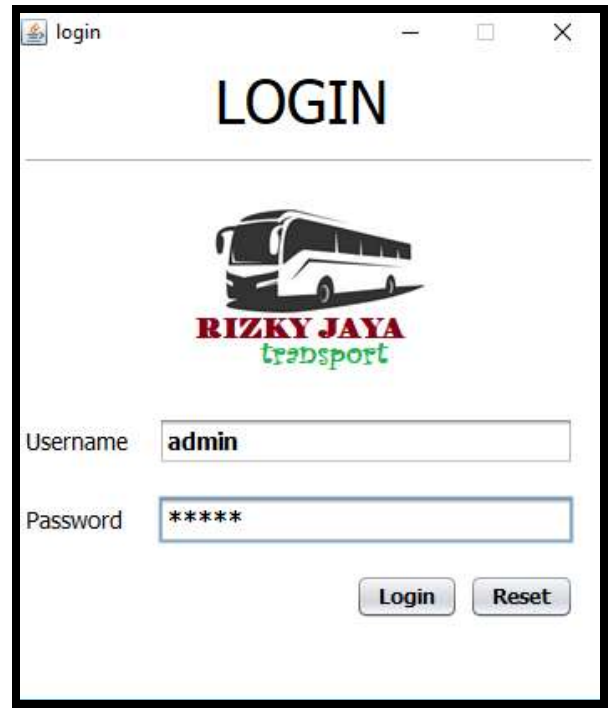

Gambar 5. Tampilan Layar Log In

Tampilan ini terdapat pada awal program. Menu login digunakan sebagai kata kunci sebelum kita memasuki program utama. Agar tidak sembarang orang dapat mengakses program ini. Sehingga dalam Form menu kerahasiaannya tetap terjaga dengan baik. Apabila pengguna dapat memasukkan nama pengguna dan kata kunci dengan tepat, maka menu utama akan tampil dan program siap untuk dijalankan.

\section{Tampilan Layar Data Penyewaan}

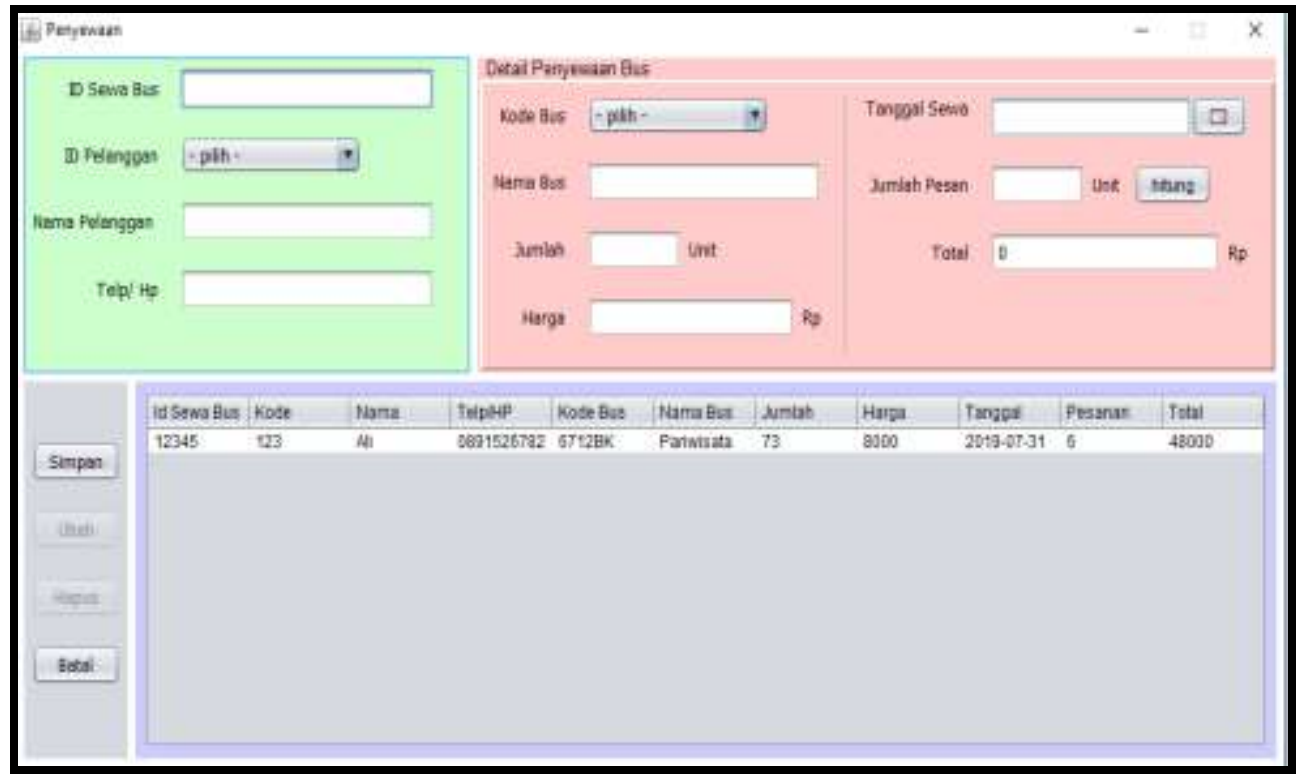

Gambar 6. Tampilan Layar Data Penyewaan 
Layar di atas menampilkan tampilan form data penyewaan. Pada layar form data penyewaan untuk menginput data penyewaan yang terdiri dari ID sewa bus, ID pelanggan, nama pelanggan, telp, kode bus, nama bus, jumlah, harga, tanggal sewa, jumlah pesan dan total.

\section{Tampilan Laporan Data Penyewaan}

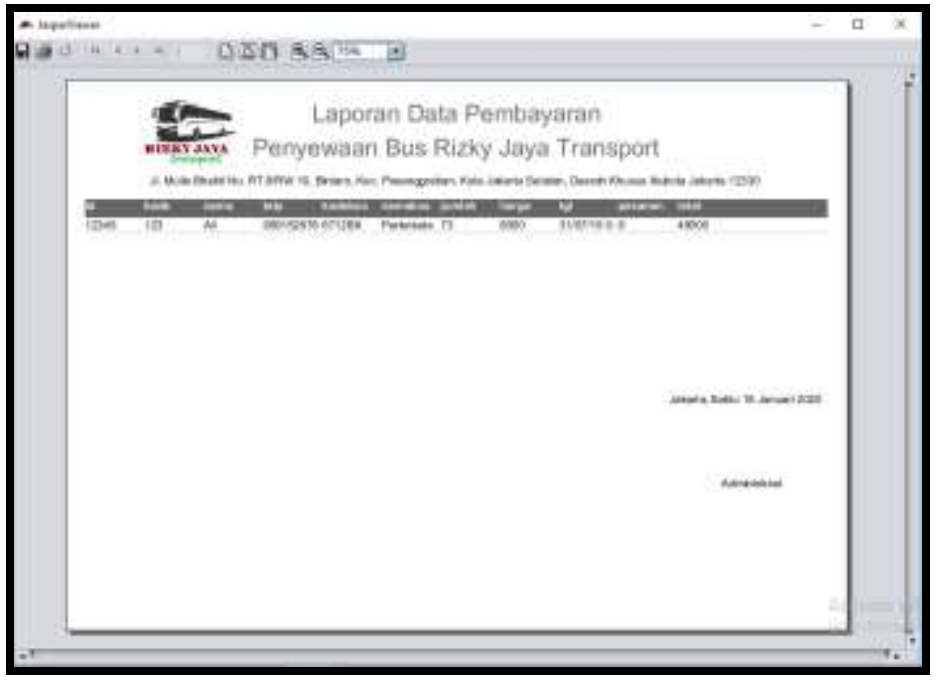

Gambar 7. Tampilan Laporan Data Penyewaan

Layar di atas menampilkan tampilan form laporan data penyewaan. Pada layar form laporan data penyewaan terdapat informasi data penyewaan yang terdiri dari ID sewa bus, ID pelanggan, nama pelanggan, telp, kode bus, nama bus, jumlah, harga, tanggal sewa, jumlah pesan dan total.

\section{SIMPULAN}

Dengan ada nya aplikasi penyewaan bus pariwisata di Rizky Jaya Transport diharapkan dapat mempermudah dalam hal pendataan penyewaan bus serta dapat meningkatkan efektifitas dalam penyajian informasi penyewaan, agar dapat menghasilkan informasi yang dibutuhkan dengan lengkap serta dipergunakan setiap saat sesuai dengan kebutuhannya. Sehingga mempermudah para penyewa dalam proses transaksi penyewaan bus.

\section{DAFTAR PUSTAKA}

Jogiyanto. (2010). Analisis \& Desain Sistem. Yogyakarta: Andi Offset.

Pahlevi, D. S. M. (2013). Tujuh Langkah Praktis Pembangunan Basis Data. Jakarta: Elex Media Komputindo.

Shalahudin, A. . R. dan. (2015). Rekayasa Perangkat Lunak Terstruktur dan Berorientasi Objek. Bandung: Informatika Bandung.

Subekti. (2014). Aneka Perjanjian. Bandung: Citra aditya Bakti.

Tata Sutabri. (2012). Analisis Sistem Informasi. Yogyakarta: Andi Offset. 